\title{
Utilizing a Simulation within an Online School Technology Leadership Course
}

\author{
Jesse Strycker \\ East Carolina University
}

\begin{abstract}
Online courses and programs have grown to become and continue to be a popular option for students. As part of an online Master's of Education in Instructional Technology program, students must complete a school technology leadership course. Leadership decision making, policy making, and how to have innovations take hold in a school settings are important things to learn about, but are even more important concepts for students to be able to practice. This case study details the reasoning behind, utilization of, adjustments to, and results from bringing a simulation into the program's online school technology leadership course. Results show that students found the simulation to provide a mostly authentic experience and grew to understand that they should view the simulation as a system, but some students were averse to risk taking and were not always able to adjust to details within the simulation that challenged their existing schema regarding technology leadership and how innovations are diffused within a school setting.
\end{abstract}

\section{Introduction}

Full-time K-12 teachers and technology staff who are interested in becoming technology leaders in their school through either postgraduate degrees or additional certification face a variety of options and challenges. Enrolling in a campus-based program may not be an option for some students. With required classes for some programs not always being offered at times compatible with a full-time work schedule and night classes not always being a practical option due to either distance or a need for greater flexibility, such as participating on different evenings, a distance education program may be the only viable option. 
Despite the recent slowing of enrollment in online classes, they remain an option that many students turn to when registering for classes or considering a program of study. Even though the year-toyear growth of online enrollment had dropped to a 13-year low of 3.7\% (Allen \& Seaman, 2015), it still indicates that additional students are taking online courses.

The increasing enrollment in online classes does not come without concern. Concerns expressed have included larger dropout rates than traditional classes (e.g., Roby, Ashe, Singh, \& Clark, 2013) and the potential for negative impacts on pedagogies and their outcomes (Allen \& Seaman, 2014). One such pedagogical concern focuses on the relative equivalency of online course offerings to their traditional, face-to-face counterparts (Platt, Raile, \& Yu, 2014). It is this concern that led the author to bring a digital simulation into the course being discussed in this study, so that there would be a practicum experience of sorts. With the popularity of online courses, different online delivery methods "have the potential to transform the landscape of higher education by expanding educational opportunities, transforming student populations, and prompting the development of new pedagogical methods” (Platt et al., 2014, p. 490). A digital simulation is one such expanded educational opportunity that is a different delivery method than what students in the course I considered have experienced in the past. The paper aims to further the understanding of how the use of a specific digital simulation was integrated into an online course through multiple implementations, how students reacted to the digital simulation, and lesson learned as a result. Further, it has been posited that there are limited data on self-reflection for online instructors in higher education (LaPrade, Gilpatrick, \& Perkins, 2014), which this paper attempts to partially address through the identified lessons learned.

\section{Literature Review}

According to Peters and Vissers (2004), simulations that have been designed for training and education purposes give participants an "artificial environment that resembles a specific real-life situation” (p. 75). Simulations can come in both traditional, nondigital forms as well as digital versions, but nondigital ones tend to appear in face-to-face settings, focus on role-play, and have the instructor serve as an active guide through the learning experience (Becker \& Parker, 2009). Digital simulations do not have these same limitations (Becker \& Parker, 2009). While the simulations resemble the real world, they serve as "a safe and artificial environment where the learner can practice decision-making and risk taking skills" (Ross \& Exposito, 2014). Part of the simulated experience has to do with how closely it resembles the reality it aims to simulate. Fidelity can be broken down into three categories: physical (the look and feel of the environment being simulated), functional (how much it acts like what is being simulated), and psychological (replication of the factors experienced in the real-world environment, such as fear or excitement) (Alexander, Brunye, Sidman, \& Weil, 2005). High fidelity may not always be necessary, as "a low level of fidelity can be sufficient as part of a larger context" (Backlund, Engstrom, Gustavsson, Lebram, \& Sjors, 2009, p. 3). As part of their development of a game-based simulator, Backlund and colleagues (2009) noted that physical and functional fidelity had the greatest impact on knowledge transfer, while the psychological fidelity had "a rather small amount of impact on the transfer element since it is a rather abstract concept” (p. 3).

Simulations have been widely used in different fields, such as business, medical, military, and science (Kovalik \& Kuo, 2012). Some simulations have included civil engineering (Ebner \& Holzinger, 2007), firefighter training (Backlund et al., 2009), leadership development (e.g., Ross \& Exposito, 2014), physics (e.g., Chen, Hong, Sung, \& Chang, 2011), medical clinical training (e.g., de Giovanni, Roberts, \& Norman, 2009), statistics (e.g., Liu, 2010), and medical education. While simulations continue to be used in different education contexts, the use of simulations or game-based learning in U.S. higher education is still in the early experimental adoption phase (Epper, Anne, \& Sean, 2012). The New Media Consortium's 2012 Horizon Report for Higher Education suggested that adoption of such game-based 
learning was just two or three years away (Johnson, Adams, \& Cummings, 2012). In the 2014 version of the report for higher education, the New Media Consortium speaks more broadly about gaming and gamification, including simulation use, as being within two or three years of adoption (Johnson, AdamsBecker, Estrada, \& Freeman, 2014). Despite the past usage, and projected future use of simulations in education, a search of the literature found only limited research (e.g., Kovalik \& Kuo, 2012) addressing the use of digital simulations in online school technology leadership courses, though some research has been conducted on using simulation with school leaders (e.g., Huang \& Kapur, 2012). Like this study, both Kovalik and Kuo as well as Huang and Kapur also utilized a simulation called the Diffusion Simulation Game.

\section{The Diffusion Simulation Game}

The Diffusion Simulation Game (DSG) has existed for over three decades, first appearing as a paper-based game (Molenda \& Rice, 1979) before its later development into an online low-fidelity simulation (Frick, Kim, Ludwig, \& Huang, 2003). Development on the DSG has continued into a second version (Lara, Myers, Frick, Aslan, \& Michaelidou, 2010). It is a beta version of this latest addition that has been used in the class focused on by this case study.

The benefits of such a simulation can come with challenges. One such concern is that instructional supports may be necessary to help learners make the most out of the DSG (Kwon, Lara, Enfield, \& Frick, 2013). Such supports can include things like prompts, feedback, debriefings, or reflections (Leemkuil, de Jong, \& Oates, 2000; Wouters \& Van Oostendorp, 2013). The absence of supports could lead to disorganized knowledge (Alfieri, Brooks, Aldrich, \& Tenenbaum, 2011), incomplete knowledge (Veenman, Bavelaar, De Wolf, \& Van Harren, 2014), and possibly cognitive overload (Kirschner, Sweller, \& Clark, 2006; Roll, Yee, \& Cervantes, 2014).

The DSG was particularly relevant to the class being discussed in this case study due to its focus on innovation diffusion, which is often a main task of school technology leaders: "Diffusion is the process by which an innovation is communicated through certain channels over time among the members of a social system" (Rogers, 2003, p. 11). While the authenticity of learning and doing things in a simulation can vary from their real-world counterparts, first-person role-play simulations can potentially provide learning opportunities when students must reconcile these differences through reflection (Jarvis, 2004). These differences and inconsistencies, sometimes the direct results from being a virtual space, can offer the greatest opportunities for learning as students work through them and reconcile differences with their own understandings (White \& Le Cornu, 2010). While the DSG focuses on peer tutoring as the innovation being diffused, which could be supported through technology integration, students are encouraged to think of the innovation as being a technology driven one to help with this mindset when approaching the simulation.

While the online master's degree offered at the author's institution offers a rigorous experience that is grounded in literature, theory, and skill development, there is only one required practicum experience that has students stepping away from their computers and working within a practicum site. To provide a technology leadership practice experience for online students, the author added a simulation experience that provided such an opportunity. Unlike most physical practicum sites, all of the students in the class are able to share the same space and reflect on their experiences. By having all students working within the same virtual site with the same factors, the only variability introduced is by the unique backgrounds and experiences of each student. This experience is highlighted in the case study described below.

\section{Context of Degree Program and Course Description}

Administration of School Technology is a required course in the online Master's of Education in Instructional Technology program at the author's institution. The program is housed within a College of 
Education and requires coursework across multiple departments. While the majority of coursework is completed within the Instructional Technology unit, students are also required to take courses in learner differentiation, educational research, and education leadership. Students must also complete two elective courses that can come from outside departments depending on their professional or academic interests.

This technology leadership course, like all of the other courses in the program, is delivered asynchronously online. Regular individual projects and one group project are completed, leading to threaded discussions at the closure of each project/unit. The instructor introduces each project/unit through an online folder, description sheet, and video overview. Each unit closes with a summation podcast that incorporates individual project feedback, course readings, and the content of threaded discussion topics. Students are given guidance on how to and are regularly encouraged to post their own podcasts and videocasts in place of traditional text postings.

The design that was inherited for this course had existed for many years, but the author found that the course was largely based on review of class materials and had students developing policies without considering specific schools. One of the main foci of the course was to have students review existing policies, critique them, and create their own. These are important aspects of developing a technology leadership skillset, but until students complete their internships, there isn't any work in the field for them as technology leaders. Logistically, adding a face-to-face field placement would be challenging. A compromise devised by the author was the use of an online digital simulation that would allow students to practice being a leader in a virtual school setting. Based on the author's own experience with it, the digital simulation selected for integration within the class was the Diffusion Simulation Game (DSG).

\section{Method}

A multiple case study design was used to inform this exploration. This is the ideal approach for undertaking such an effort because, as Merriam (2009) states, "this design is chosen precisely because researchers are interested in insight, discovery, and interpretation rather than hypothesis testing” (p. 42). As a result, there is limited generalizability to this study, but a greater understanding of the phenomenon of the case being explored is developed (Merriam, 2009). The multiple case study design allowed for the organization of each semester under examination to be treated as its own case, with the bounded phenomena being the integration of a digital simulation and subsequent adjustments to its implementation. With this organization in place, constant comparative analysis was used to analyze the data. Analysis of the data revealed three themes and led to the identification of five lessons learned.

\section{Participants}

A total of 138 instructional technology students completed a required educational technology course in either the fall or spring semesters between spring 2012 and spring 2014. Five instructional technology students from the department's other instructional technology program and one educational leadership student took the course as an elective, leading to a total of 144 students being considered as part of this study.

\section{Data Sources}

The data sources for this study included student reflections and responses from class discussion forums and student responses to an optional anonymous survey. The reflection and response data consisted of the 127 completed student reflections and 104 student responses to the posted reflections (not all students completed the required reflections or responses). Reflections were submitted either in text form, text plus screenshots of play sessions, or in video form. Only three students completed the optional anonymous survey that was provided. For an example student reflection, see Appendix A. 


\section{Data Collection Procedure}

Completing the simulation activity required students to carry out three steps. Students had to first sign up for the DSG and complete a minimum of three unique play sessions from start to finish. Students then had to post in a dedicated threaded discussion forum and report the following for each play session: the strategies they had employed, why they had used these strategies, and the results they had achieved, preferably including screen captures of final results. Students also had to reflect on the overall experience and its authenticity. Finally, students had to respond to a minimum of two classmates' reflection postings. As part of this step, students were encouraged to offer suggestions to help classmates be more successful in subsequent play sessions and make any real-world connections they could. For students who did not feel that they could express all of their thoughts on the simulation experience, an anonymous survey was also provided. The text from all of the postings, responses, and surveys was copied into a single document for each semester for analysis.

\section{Data Analysis}

The data analysis took place through two steps: first examining each case individually and then performing analysis across cases. The lens used to inform the initial analysis was informed by the questions students were asked to address, which covered strategies used and why, the experience itself, and the authenticity of the experience. All of the postings were first read without making notes to develop a holistic understanding of student reactions. During a second reading, margin notes were maintained for each case, which were grouped into codes and gradually collapsed into themes. A sampling of this process for one of the themes, Mostly Authentic, is provided below (see Table 1).

Table 1

Examples of Collapsing Notes to Codes to a Theme

\begin{tabular}{lll}
\hline Margin notes & Codes & Theme \\
\hline $\begin{array}{l}\text { Very authentic } \\
\text { Like the student's old school }\end{array}$ & Pretty authentic & \\
Somewhat close to experience & & Mostly Authentic \\
Just like real life & \\
$\begin{array}{l}\text { Accurate for teachers in school, } \\
\text { but not the principal }\end{array}$ & Mostly accurate & \\
Pretty accurate & \\
\hline
\end{tabular}

Between-case analyses consisted of reviewing the codes and themes for each case for commonalities. Additionally, changes in how the digital simulation was implemented each semester were also considered (see Table 2). Codes and themes informed the formation of the cross-case themes, but changes between semesters informed lessons learned. 
Utilizing a Simulation within an Online School Technology Leadership Course

Table 2

Simulation Implementation Changes Between Semesters

\begin{tabular}{|c|c|c|c|c|}
\hline Spring 2012 & Fall 2012 & Spring 2013 & Fall 2013 & Spring 2014 \\
\hline \multicolumn{5}{|l|}{$\begin{array}{l}\text { Introduction of } \\
\text { simulation }\end{array}$} \\
\hline No scaffolding & $\begin{array}{l}\text { Limited } \\
\text { scaffolding } \\
\text { (additional } \\
\text { guidance for } \\
\text { getting started) }\end{array}$ & $\begin{array}{l}\text { Moderate } \\
\text { scaffolding } \\
\text { (additional } \\
\text { guidance for } \\
\text { posting of } \\
\text { reflection posting) }\end{array}$ & $\begin{array}{l}\text { Full scaffolding } \\
\text { (additional } \\
\text { guidance offered } \\
\text { for how to post } \\
\text { videos and further } \\
\text { discuss } \\
\text { reflections) }\end{array}$ & $\begin{array}{l}\text { Stronger } \\
\text { encouragement to } \\
\text { use screencasts or } \\
\text { vlogs to post } \\
\text { reflections }\end{array}$ \\
\hline $\begin{array}{l}\text { Feedback at end } \\
\text { of experience }\end{array}$ & $\begin{array}{l}\text { Limited feedback } \\
\text { during experience } \\
\text { (e.g., hints) }\end{array}$ & $\begin{array}{l}\text { Moderate } \\
\text { feedback during } \\
\text { experience (e.g., } \\
\text { broader } \\
\text { suggestions } \\
\text { towards } \\
\text { approaches) }\end{array}$ & $\begin{array}{l}\text { Full feedback } \\
\text { during experience } \\
\text { (e.g., specific } \\
\text { commenting on } \\
\text { approaches) }\end{array}$ & \\
\hline $\begin{array}{l}\text { During final week } \\
\text { of semester }\end{array}$ & $\begin{array}{l}\text { Overlapping of } \\
\text { last two weeks of } \\
\text { semester }\end{array}$ & & $\begin{array}{l}\text { Overlapping of } \\
\text { third and second } \\
\text { to last weeks of } \\
\text { semester }\end{array}$ & \\
\hline
\end{tabular}

\section{Results}

In analyzing the different data sources described earlier from the initial use of the DSG and subsequent iterations of class use, three themes emerged: the Simulation as a System, Mostly Authentic, and a Lack of Risk Taking.

\section{The Simulation as a System}

One of the most frequent occurrences with students during their first play session was to follow a loose plan of seeing what would happen when they would do $x, y$, or $z$. Students that followed this kind of approach were almost equally divided by whether or not they also read the directions provided as part of the simulation. Of those students who didn't read the directions initially, the majority did prior to their second session. However, even when they understood the rules, some students still just tried different combinations of activities without a plan. It wasn't until students thought of the virtual school as a real system, like their own schools or as systems that had been described in course readings, that they started to have success. For example: 
The first time I played, I had 7 adopters at the end of the game. At this point, I really didn't have a strategy. I pretty much clicked on random people and activities just to see how the game was played. (Fall 2013)

I was never able to get the Principal on board first. That was one of my goals but I think I would have to play the game again and look more at the social network, lunch mates and other informational tools on the principal. I actually took screen shots of the first round game log and based my strategy for the second round on this. Like I said, the game is not predictable at all! Everyone behaved differently! I thought I had the staff personalities, likes and dislikes figured out, but I didn’t! (Spring 2012)

I first focused on getting to know all individuals (learning about them and talking to them at least once) along with winning over the secretary and custodian right away. I learned all groupings and social networks and focused on the early adapters that I learned would adapt from previous rounds. The principal was part of this group who became my third adapter early on, which was extremely helpful. I used a variety of different demonstrations and strategies to gain support by focusing on group members that will inspire other school staff who they associate with. This trickle down effect was the key. (Spring 2013)

The three quotes above illustrate different examples of this theme. In the first quote a student describes clicking through options essentially to see what happens and how the simulation reacts. In the second quote a student describes going back over their actions from the first play session and expresses frustration when the new strategy doesn't yield the hoped-for results. This is an example of misunderstanding the system. The final quote shows a student in their third session having figured out how the system works and using its own flow for a "trickle down" effect.

\section{Mostly Authentic}

With the exception of only a few students, the majority of students felt the simulation was mostly authentic. The low fidelity of the simulation did not appear as a point of contention with any students. The biggest points of contention revolved around time and access. One of the early activities of the DSG is the gathering of information about faculty and staff in the school. Players are limited to finding out about only five people at a time. Students felt that they could have talked to more than five people in a week. Many students also sought the support of the school's principal but found him difficult to connect with, as he was often unavailable. Many students felt that while a principal was a busy person, it would have not been that difficult to meet with them at least a few times during any given month. The next most frequent contention involved the power of gatekeepers within the school setting. As students worked through different play sessions, they began to understand that in the DSG's school setting certain people needed to be approached before any success could be found with others or in carrying out certain actions within the DSG. While other concerns emerged, such as the feasibility of repeated professional development or site visits to other schools, none were as universal as those concerns already addressed. For example:

I didn't know what to expect when I read this assignment, but this game was really fun. It hurt a little to see my weeks sucked away, but that is really what happens. I've seen that this year as I've tried to get my school to adopt Google Apps. Some strategies work better than others; in my experiences, workshops were only so helpful. It required more personal relationships and conversations, which was reflected in this game. (Fall 2014)

Just like in a real school, be nice to your janitor and your secretary. I had the same problem with the principal. The first time, I was able to get him on board but I am not sure how. The second time and third time I came close but was never able to get him to adopt. I am glad that my 
principal is not that hard to crack. But, I will also tell you that this game is kind of like school. You have some teachers that are more influential than others. (Spring 2012)

It seemed fairly realistic in that there are people that are quick to adopt things and try new things and others who basically need to be dragged kicking and screaming. The only thing that was a little unrealistic was the amount of power the janitor had. Other than that, things that happened seem fairly real. (Spring 2014)

During the first play through I didn't think the simulation was very similar to my own experiences at my school, mainly because I'd never have to jump through so many hoops to talk to my principal-she's very approachable, and I can talk to her basically any time I want. The more I played through the game and thought about it, I realized that much of the game really is similar to schools in real life, especially the way staff members interact and the close groups that form (lunch buddies at school and social groups gathering outside of school). (Fall 2012)

The four quotes above illustrate different aspects of this theme. In the first quote the student acknowledges how systemic change efforts can be time consuming and that different strategies can be effective, though they haven't always found workshops to be as effective as their other efforts. The remaining three quotes talk about access to the principal and the access of others; while the situations might not be the same as their own professional settings, students did note the different levels of influence held by others in school settings. Even with the acknowledgement of that similarity, some frustration and discomfiture come through.

\section{Lack of Risk Taking}

Even with the DSG having no real-world risks or negatives associated with it, full credit was received for completion of the activity regardless of student results achieved. A full third of the students avoided time-consuming activities in the DSG in favor of being able to complete additional less costly activities. There were also two activities available to students, Confrontation and Compulsion, which were only tried by a small number of students. The lack of interest in these activities was due in equal parts to the negative phrasing (students knew that confrontation and compulsion were unsuccessful when others used those strategies on them as teachers) and to students not knowing what would happen if they chose these activities. For example:

I also noticed that talking to people had a consistent positive impact, even if it was a little at a time. It's always harder for someone to say "no" in person. So, demonstrations, site visits, piloting all work. But, talking to people can seal the deal. (Fall 2012)

I wasn't bold enough to choose compulsion or confrontation because it cost too much. I can’t imagine the confrontation would damage more than help though. (Spring 2013)

I was wondering what happened when compulsion was chosen. I was curious, but not compulsive. (Fall 2013)

I never even thought of trying confrontation and compulsion because it "cost” too much! (Spring 2014)

The four quotes illustrate different aspects of this theme. The first quote addresses the difference in how time consuming different activities are. Talking takes only a week in the simulation, while activities such as a site visit take several. In some instances, as this student notes, it is safer to go with the guaranteed results of talking instead of a more time-consuming activity. The remaining three quotes 
address concerns over using the confrontation or compulsion activities. As is the case from semester to semester, despite a lack of real-world consequence, even students who are curious about these activities will rarely try them.

\section{Lessons Learned}

Students had a difficult time not working from the schemas they had established at their past and current schools. While most students used their own schema as a reference for thinking about the staff and faculty in the DSG, they quickly discovered that the people they depended on in their own schools were not always the same in the DSG school setting. Some students could not let go of this and continued to express frustration in certain faculty and staff not responding as they "should." Conversely, some students applied more general schemas that they could not move beyond. This most clearly came through in the belief that certain gatekeepers in the DSG setting could not and should not have such levels of influence because students had never known a school setting where such a situation was the case. The instructor will need to make additional efforts to make it clearer that the DSG is simulating a school environment that they may not have any experience with and that they must act accordingly.

Even if a simulation has its own instructions and videos that talk students through how to use it, students will require additional support. The first semester the simulation was utilized, only a cursory overview and instructions were provided beyond those provided by the simulation's developers. Due to the number of questions asked and concerns expressed, additional scaffolding was added in each of the next three semesters. The latest version of the activity that this study examined included a text overview, a video overview, an explanation of common problems students have getting started with the activity, and more detailed prompts in the discussion forum about what students should be posting, as well as several examples of how to present their results.

Students are more likely to consider feedback and apply it to additional play sessions if it is shared during the activity than if it is shared at the end of the activity. Feedback used to be offered by the author at the end of the activity to avoid biasing how students experienced the DSG. The problem that arose with the timing of feedback was that only about a third of the students would actively consider the feedback and apply it to additional play sessions. When provided with feedback as soon as they started posting their play session notes, students and their classmates were more likely to consider it.

This activity works better in the last few weeks of the class than as the final activity of the class. One iteration had the experience at the end of the course as a final activity that was intended to both be a close-of-semester reflective practice as well as an enjoyable way to end the course. The semester this was tested resulted in the highest number of students not completing the activity, playing only the minimum number of sessions, and only showing limited engagement within their own reflections and in responding to classmates' postings. The best time to run this activity has proven to be during the window of time between the final regular class project and the final, summative class project. During this time frame, students are in a reflective mode as they revise past assignments toward completing their final project. This particularly reflective time of semester seems to inform their approach to the DSG activity.

Students outside of K-12 education contexts have difficulty working within the simulation. This is the lesson that has been the most difficult to do anything about. As a school technology leadership course, it makes sense for the simulation to be set in a K-12 school setting. Some students have been able to better imagine the context of the DSG as relevant to their unique settings, but students who take the course as an elective for the MS program have found it challenging to apply the experience to a corporate environment. In future iterations of using this simulation in the course, the instructor could provide additional scaffolding for students outside of K-12 settings to help them relate it better to higher education and corporate settings. 


\section{Discussion}

It has been suggested by some (e.g., Ebner \& Holzinger, 2007) that simulations have not been observed as widely in higher education as in other fields, and that adoption into higher education is still in an early experimental phase (Epper et al., 2014). This case study offers an additional example of simulation use in higher education, specifically in the area of school technology leadership education. The DSG dates back many years (Molenda \& Rice, 1979) and is continuing to find use in additional higher education settings (e.g., Huang \& Kapur, 2012; Kovalik \& Kuo, 2012) beyond the class that this case study focused on.

Some researchers (Kwon et al., 2013) have indicated that educational supports may be necessary to get the most out of the DSG. Kwon and colleagues noted that participants indicated prompts helped them to complete the game, but their findings did not suggest improved performance. Educational supports can include things like prompts, feedback, debriefings, or reflections (Leemkuil, de Jong, \& Oates, 2000; Wouters \& Van Oostendorp, 2013). The exploration of this case found that supports were helpful in helping students to be successful with the simulation experience. While the DSG has its own prompts, which can be overlooked by students wanting to try things out, the inclusion of prompts helped to orient students in this study to better understand what was going on in the DSG and how they needed to approach their play sessions. Immediate feedback in the threaded discussion forum as students posted their results and strategies led to students being more likely to incorporate feedback into remaining or additional play sessions. Student reflections, especially those of students with the greatest success in the DSG, led to some students incorporating classmates' strategies for greater success. Educational supports have continued to prove useful through different iterations of this activity and should be considered by others considering bringing the DSG into their own classes.

It has also been suggested that the differences from reality exhibited by simulations present good opportunities for learning to take place (Jarvis, 2004; White \& Le Cornu, 2010). The differences and inconsistencies led to a number of deep conversations in the threaded discussion board regarding appropriate strategies for implementing change in a school setting, the role of gatekeepers, the importance of social influence, and the accessibility of administrators. Some students could not get past the differences presented in the DSG. This seemed to go beyond concerns like disorganized knowledge (Alfieri et al., 2011), incomplete knowledge (Veenman et al., 2014), or even cognitive overload (Kirschner et al., 2006; Roll et al., 2014). Instead, what seemed to be going on was the conflict with an entrenched belief system that had not been sufficiently challenged (e.g., Sadera \& Hargrave, 2005) about how a social network works within a school setting or how a technology innovation might take hold in the same setting. Some areas of conflict included displeasure with the amount of time that certain activities took, such as talking to colleagues, and the possibility that a secretary or janitor might have any type of gatekeeper authority that could impede a technology leader from accomplishing their goals. Students in the class from outside of K-12 educational settings also had some difficulty in relating outside experiences to and from the DSG's school setting. Additional education supports may be necessary to help those students with entrenched belief systems or difficulty in generalizing experiences to gain more from the experience provided by a digital simulation like the DSG. The self-reflection elements of this study should aid in better teaching (LaPrade et al., 2014) using this simulation in future iterations of its implementation.

\section{Limitations}

This study focused on the experiences of integrating a specific digital simulation into a specific online technology leadership course over several semesters at one university and, as such, will have limited generalizability to other online classes at other universities. The detailed context and thought 
processes are presented to help provide a greater possibility for transferability of some of this study's findings to other unique contexts. Furthermore, the student reflections were part of a class assignment, which may have influenced the tone of the reflections. An anonymous survey option was provided as an outlet for additional reflection on the simulation to limit the potential fear of being critical, but only three students completed those surveys. This may be indicative of students feeling they had already adequately reflected, still wishing to maintain a positive tone, or perhaps not being interested in completing an additional step.

Further studies should consider the implementation of other kinds of digital simulations in online courses at other universities across the country. Some variables that could be considered might include the purpose for which the digital simulation was implemented, how much and what types of scaffolding were provided, and when in the course the simulation was completed.

\section{Conclusion}

This case study described the reasoning behind, implementation of, themes that emerged from, and lessons learned from the use of a digital simulation in an online technology leadership course. As part of this course, students had to complete three play sessions within the simulation and keep track of their thought processes, results, and reflections on each session. Students then had to post their notes to a threaded online discussion forum and respond to similar postings by classmates who had completed their own play sessions and postings.

Through a discussion of observed themes and lessons learned, this article demonstrates how the use of a digital simulation allowed students to have a virtual field experience where they could try out different leadership approaches in a setting they weren't familiar with and reflect on their practices. Once students got beyond thinking of the simulation as a simple game and instead thought of it as an interconnected system, they started to have successful sessions. Results from this study show that students developed a greater understanding of what effect their leadership action might have in a school setting other than the ones they were familiar with. Many students reflected that the simulation was mostly authentic, but some had difficulty accepting some of the occurrences within the simulation because they ran counter to their own real-world experiences. Despite these differences and the awareness that it was only a simulation, few students were willing to employ what they perceived as risky or time-consuming activities. Additional efforts will need to be made in the next iteration of this activity to encourage students to not be so risk averse in the simulation.

The goal of this case study was to illustrate the thought process and iterations of bringing a digital simulation into an online technology leadership course to provide a pseudo field experience and an opportunity for reflective practice as technology leaders. Lessons learned in this case study might be useful to others who have considered bringing a digital simulation into their own online courses or as a learning exercise for new technology leaders in K-12 school settings. This case study could also provide an example for how technology leaders in other professional settings could develop their reflective practice abilities in a risk-free setting at their convenience.

\section{References}

Allen, I. E., \& Seaman, J. (2014, January). Grade change: Tracking online education in the United States. Babson Park, MA: Babson Survey Research Group. Retrieved from http://www.onlinelearningsurvey.com/reports/gradechange.pdf 
Utilizing a Simulation within an Online School Technology Leadership Course

Allen, I. E., \& Seaman, J. (2015, February). Grade level: Tracking online education in the United States, 2014. Babson Park, MA: Babson Survey Research Group. Retrieved from http://onlinelearningconsortium.org/read/survey-reports-2014/

Alfieri, L., Brooks, P. J., Aldrich, N. J., \& Tenenbaum, H. R. (2011). Does discovery-based instruction enhance learning? Journal of Educational Psychology, 103(1), 1.

Backlund, P., Engström, H., Gustavsson, M., Johannesson, M., Lebram, M., \& Sjörs, E. (2009).

Sidh: A game-based architecture for a training simulator. International Journal of Computer Games Technology, 2009.

Becker, K., \& Parker, J. R. (2009). A simulation primer. In D. Gibson \& Y. Baek (Eds.), Digital

simulations for improving education: Learning through artificial teaching environments. Hershey, NY: Information Science Reference.

Ebner, M., \& Holzinger, A. (2007). Successful implementation of user-centered game

based learning in higher education: An example from civil engineering. Computers \& Education, 49, 873-890. doi:10.1016/j.compedu.2005.11.026

Frick, T., Kim, K.-J., Ludwig, B., \& Huang, R. (2003). A web simulation on educational change: Challenges and solutions for development. Paper presented at the meeting of the Association for Educational Communication and Technology, Anaheim, CA. Retrieved from https://www.indiana.edu/ tedfrick/aect2003/frick_kim_ludwig_huang.pdf

Huang, J., \& Kapur, M. (2012). Learning innovation diffusion as complex adaptive systems through model building, simulation, game play and reflections. In J. van Aalst, K. Thompson, M. J. Jacobson, \& P. Reimann (Eds.), Proceedings of the International Conference of the Learning Sciences (ICLS) 2012 (Part 1, pp. 259-266). Sydney, Australia: International Society of the Learning Sciences. Retrieved from http://repository.nie.edu.sg/bitstream/10497/14439/1/ICLS2012-259-HuangJ_a.pdf

Jarvis, P. (2004). Adult \& continuing education (3rd ed.). London: Routledge.

Johnson, L., Adams, S., \& Cummings, M. (2012). NMC horizon report: 2012 higher education edition. Austin, TX: The New Media Consortium. Retrieved from http://www.nmc.org/publications/horizon-report-2012-higher-ed-edition

Johnson, L., Adams-Becker, S., Estrada, V., \& Freeman, A. (2014). NMC horizon report: 2014 higher education edition. Austin, TX: The New Media Consortium. Retrieved from http://cdn.nmc.org/media/2014-nmc-horizon-report-he-EN-SC.pdf

Kirschner, P. A., Sweller, J., \& Clark, R. E. (2006). Why minimal guidance during instruction does not work: An analysis of the failure of constructivist, discovery, problem-based, experiential, and inquiry-based teaching. Educational Psychologist, 41(2), 75-86. doi:10.1207/s15326985ep4102_1

Kovalik, C. L., \& Kuo, C. (2012). Innovation diffusion: Learner benefits and instructor insights with the diffusion simulation game. Simulation \& Gaming, 43(6), 803-824. doi:10.1177/1046878112444577 
Utilizing a Simulation within an Online School Technology Leadership Course

Kwon, S., Lara, M., Enfield, J., \& Frick, T. (2013). Design and evaluation of a prompting

instrument to support learning within the diffusion simulation game. Journal of Educational Technology Systems, 41(3), 231-253.

Lara, M., Myers, R., Frick, T. W., Aslan, S., \& Michaelidou, T. (2010). A design case: Developing an enhanced version of the diffusion simulation game. International Journal of Designs for Learning, 1(1) 40-54. doi:10.2190/ET.41.3.c

LaPrade, K., Gilpatrick, M., \& Perkins, D. (2014). Impact of reflective practice on online teaching performance in higher education. Journal of Online Learning and Teaching, 10(4), 625. Retrieved from http://jolt.merlot.org/vol10no4/Gilpatrick_1214.pdf

Leemkuil, H., de Jong, T., \& Oates, S. (2000). Review of educational use of games and simulations. Twente: University of Twente. Retrieved December 5, 2014 from http://kits.edte.utwente.nl/documents/D1.pdf

Merriam, S. B. (2009). Qualitative research: A guide to design and implementation. San Francisco, CA: Jossey-Bass.

Molenda, M., \& Rice, J. M. (1979). The diffusion simulation game. Simulation and Games, 10(4), pp. 459-467. doi:10.1177/104687817901000407

Peters, V. A. M., \& Vissers, G. A. N. (2004). A simple classification model for debriefing simulation games. Simulation Gaming, 35(1), pp. 70-84. doi:10.1177/1046878103253719

Platt, C. A., Raile, A. N. W., \& Yu, N. (2014). Virtually the same?: Student perceptions of the equivalence of online classes to face-to-face classes. MERLOT Journal of Online Learning and Teaching, 10(3), 489-503.

Roby, T., Ashe, S., Singh, N., \& Clark, C. (2013). Shaping the online experience: How administrators can influence student and instructor perceptions through policy and practice. The Internet and Higher Education, 17, 29-37. doi:10.1016/j.iheduc.2012.09.004

Rogers, E. M. (2003). Diffusion of innovations (5th ed.). New York: The Free Press.

Roll, I., Yee, N., \& Cervantes, A. (2014). Not a magic bullet: The effect of scaffolding on knowledge and attitudes in online simulations. In International Conference of the Learning Sciences.

Ross, D. B., \& Exposito, J. A. (2014). A dual perspective in leadership and decision making through a distance learning simulated city. International Journal of Education and Social Science, 1(3), 113. Retrieved from http://www.ijessnet.com/wp-content/uploads/2014/10/1.pdf

Sadera, W., \& Hargrave, C. (2005). Conceptual change in teacher technology preparation. In C. Vrasidas, \& G. V. Glass (Eds.), Preparing teachers to teach with technology: Current perspectives on applied information technologies. Greenwich, CT: Information Age Publishing.

Veenman, M. V., Bavelaar, L., De Wolf, L., \& Van Haaren, M. G. (2014). The on-line assessment of metacognitive skills in a computerized learning environment. Learning and Individual Differences, 29, 123-130. 
White, D., \& La Cornu, A. (2010). Eventedness and disjuncture in virtual worlds. Educational Research, 52(2), 183-196. doi:10.1080/00131881.2010.482755

Whitton, N. (2010). Learning with digital games: A practical guide to engage students in higher education. New York: Routledge.

Wouters, P., \& Van Oostendorp, H. (2013). A meta-analytic review of the role of instructional support in game-based learning. Computers \& Education, 60(1), 412-425.

\section{Appendix A: A Partial Student Reflection from Spring 2014}

Due to the depth of this student reflection, only the adjustment between play sessions two and three as well as the final reflection are included. The student also included a screen capture of the results from their first play session.

\section{Explanations of the Adjustments:}

It takes 5 weeks to gather information on all staff members. I will do this initially. I will talk to the Secretary so I am able to talk with the principal to get approval to continue with the diffusion activities. I will contact and talk to the influential staff members first and focus on "buy in" from them. I will then focus on bringing awareness to all staff members, including the janitor (I left him out on Trial \#2). Then I think the important step is for the staff members to see the innovation in action. So I will conduct two site visits. The first site visit will be with the respected and influential staff members to confirm "buy in." The second site visits will combined some motivating staff members and some more reluctant teachers. I am going to conduct pilot tests in rooms of teachers $\mathrm{M}$ and $\mathrm{F}$. I am going to focus on the influential staff member $\mathrm{H}$, early in the game. I am also going to conduct demonstrations in rooms $\mathrm{M}$ and $\mathrm{F}$, early in the game due to its extreme effectiveness.

DSG-Try

Adopters: 13 I went with my adjusted strategy. I gathered all personal information, took 5 weeks. I then talked to the Secretary and got her "on board" initially. That was a good move. I decided to wait and approach the principal later after I had talked to some of the key staff members and created some interest. I talked to two negative staff members (E) and (K), to avoid opposition. That was a good move, as well. I did choose to use the print diffusion activity but with no results. I decided not to use that activity any more. Not worth losing a week of time. Another part of my strategy that yielded good results was waiting to contact the principal until the key stakeholders were aware of the innovation. He then gave his permission to proceed with additional diffusion activities. I conducted three site visits and the results were great! It was well worth using 12 weeks to conduct site visits. Again, the pilot tests were not that successful. Once I had adopters (and they were my most influential staff members), I conducted demonstrations in their classrooms and that yielded great results. Targeted those respected and influential staff members was a good strategy. I was disappointed that I didn't get more adopters and it was less than my trial 2. I felt that my strategy during the third trial would have gotten more adopters and was more effective. But, we can’t predict human nature!!

\section{Reflections:}

Well, just as in the real world, the principal is always a key stakeholder, very influential, and often difficult to get in to talk with them. School secretaries often are at the heart of the school and has their "pulse" on what is going on. Having the secretary's support is imperative! Secretaries and janitors, you want them happy and content. I believe that it is very important to make the entire staff aware of a new innovation. Everyone wants to feel important and feel a part of the process. Often the negative people or more reluctant teachers are the ones that appreciate you talking the time to talk to them and elicit their opinions. I found that true in the simulation as well as in real life situations. At least if you are able to get 
them to entertain the thought of a new idea and not create conflict and opposition among the staff, then you have been successful with this group of stakeholders, for now. It is also imperative that you get the respected and influential staff members "on board", enthusiastic, and motivated to try new ideas. As in the simulation, teachers will pay attention and be more interested in ideas that respected colleagues deem valuable. In a school setting, lunch mates, committee members and teachers who socialize with each other is paramount to ideas being accepted. A lot of discussions are held over lunch, during/after committee meetings and at the bowling alley on the weekends. These conversations can be influential in the acceptance of news ideas and innovations. I was not surprised that the diffusion activity of site visits was a very powerful influence on adopters. I have found that teachers want to see new initiatives in action, just as they did in the simulation. Especially if the site visits demonstrates the successes of the initiatives and is led by motivating supporters. As in the simulation, it is important that you know your staff members, personally, and can relate to them. In the simulation, pilot tests were not that successful; however, I find that they are successful in real life situations. Most teachers will welcome you into their classrooms to teach. This not only allows them to see the new initiative in action, it also gives the teacher "a break". I believe this shows the teacher that the new innovation is “doable" and it doesn't seem so foreign or daunting. So, again, I feel that pilot test are more influential in real life settings than they were in the simulation. Demonstrations were a great influence in the simulation and they are also powerful in a school setting. Demonstrations are worth the effort it takes to organize coverage for classes, etc. Conducting demonstrations in classes with motivated teachers is paramount. You want the demonstration to be a positive experience. Choose respected and influential teachers' classrooms to have your demonstrations. Other staff members will be more incline to be interested if someone they respect is considering this new initiative. When approaching a new initiative stakeholders must feel valued and included in the process.

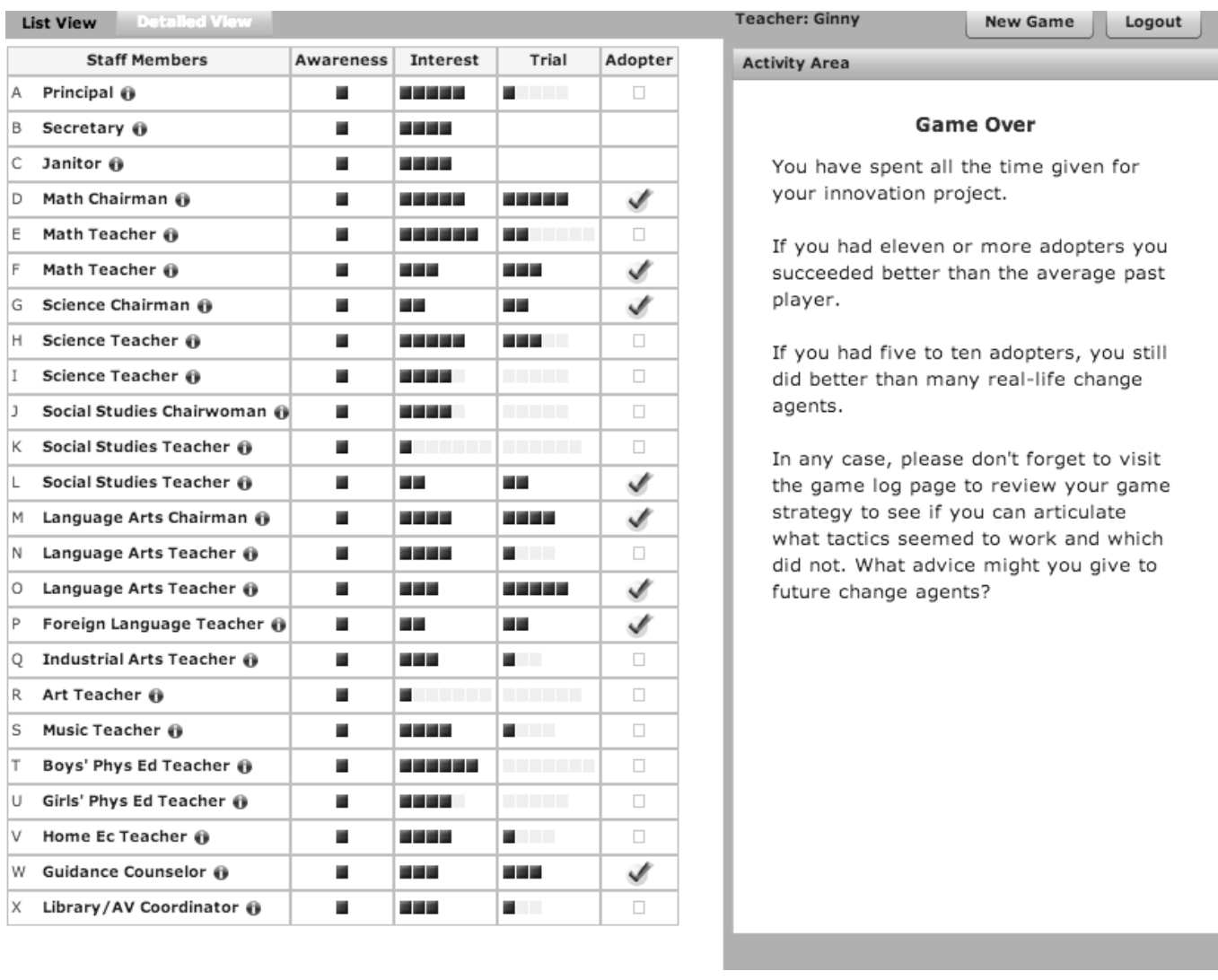

Figure 1. Example screenshot of a student’s first play session results. 